\title{
Viabilidade econômica de tourinhos terminados em confinamento alimentados com diferentes teores de caroço de algodão em dietas elaboradas com co-produtos agroindustriais
}

\section{Economic viability of bulls finished in feedlot fed with different levels of cottonseed in diets prepared with agro-industrial by- products}

\author{
Luiz Juliano Valério Geron ${ }^{1 *}$; Daiane Caroline Moura²; Deivison Novaes Rodrigues ${ }^{3}$; \\ Edson Júnior Heitor Paula ${ }^{1}$; Raquel Joana Trautmann-Machado ${ }^{4}$; Jocilaine Garcia ${ }^{1}$; \\ Alline Mariá Schumann ${ }^{5}$; Dilma Alves Silva ${ }^{1}$
}

\begin{abstract}
Resumo
Avaliou-se a viabilidade econômica da utilização de rações contendo diferentes teores de caroço de algodão - CRA $(0 \% ; 10 \% ; 20 \%$ e $30 \%)$, em tourinhos confinados. As rações continham $85 \%$ de concentrado (casca do grão de soja e farelo de soja) e $15 \%$ de volumoso (bagaço de cana-de-açúcar hidrolisado). Foram utilizados 32 tourinhos da raça Nelore, com idade média de 36 meses e com peso corporal (PC) inicial de $424 \pm 25 \mathrm{~kg}$, confinados por 90 dias. Foi utilizado delineamento experimental inteiramente casualizado. Os dados de ganho médio diário (GMD) dos diferentes tratamentos foram submetidos à análise de variância e as diferenças obtidas foram analisadas por equação de regressão a $5 \%$ de significância. Os diferentes teores de CRA não alteram ( $p>0,05)$ o GMD dos tourinhos em terminados em confinamento. A diferença obtida no valor da receita total por carcaça foi de $\mathrm{R} \$ 50,60$ entre os níveis de $0 \%$ e $10 \%$ de CRA e de R $\$ 44,16$ para os níveis $0 \%$ e $30 \%$ de CRA. Foi verificado que os tourinhos alimentados com o nível com $30 \%$ de CRA apresentaram uma variação de $75 \%$ a mais na receita $(\mathrm{R} \$) \mathrm{kg}^{-1}$ de carcaça em relação ao nível com $0 \%$ de CRA, ou seja, uma diferença de $\mathrm{R} \$ 0,58$ $\mathrm{kg}^{-1}$ de carcaça entre esses níveis, respectivamente, o que gerou uma diferença de $\mathrm{R} \$ 5.623,80$ entre a receita líquida por mês para o nível de $0 \%$ de CRA (R \$ 941,37) e o nível de 30\% de CRA (R $\$ 6.565,17)$. A ração com $30 \%$ de CRA apresentou um custo de $\mathrm{R} \$ 0,08 \mathrm{~kg}^{-1}$ menor em relação à ração com $0 \%$ de CRA. Portanto a utilização de até $30 \%$ de CRA na alimentação de tourinhos confinados mantém o GMD e pode gerar uma receita líquida mês ${ }^{-1}$ maior em $85 \%$ em relação a rações sem caroço de algodão.

Palavras-chave: Custo operacional, ganho médio diário, receita líquida
\end{abstract}

\begin{abstract}
Evaluated the economic viability of different levels of inclusion of cottonseed - COS $(0 \%, 10 \%, 20 \%$, $30 \%$ ) on feed for bulls finshed in feedlot. The diets containing $85 \%$ concentrate (soybean hulls $-\mathrm{SOH}$,
\end{abstract}

\footnotetext{
${ }^{1}$ Profs., Universidade do Estado de Mato Grosso, UNEMAT, Pontes e Lacerda, MT. E-mail: ljgeron@yahoo.com.br; edsonzootecnista@msn.com; jo@unemat.br; dilmavet@hotmail.com

${ }^{2}$ Discente, UFMT, Cuiabá, MT. E-mail: daiane_caroline@zootecnista.com.br

${ }^{3}$ M.e da Suprema Nutrição Animal, SNA, Pontes e Lacerda, MT. E-mail: deivisonnr@hotmail.com

${ }^{4}$ M.e do Instituto de Desenvolvimento Agropecuário do Mato Grosso, INDEA, Pontes e Lacerda, MT. E-mail: raquel_trautmann@, hotmail.com

${ }^{5}$ Discente do Centro de Energia Nuclear na Agricultura, CENA, Piracicaba, SP. E-mail: allineschumann@yahoo.com.br

* Autor para correspondência
} 
soybean meal SOM) and 15\% rouglage (sugar cane bagasse, sugar-hydrolyzed - SHY). Were used 32 Nelore bulls with a mean age of 36 months and body weight (BW) initial mean of $424 \pm 25 \mathrm{~kg}$ for 90 days. We used a completely randomized design. Data on average daily gain (ADG) of different treatments were submitted to analysis of variance and were tested by means of regression analysis considering 5\% significance level. The different levels of COS did not change ( $p>0.05$ ) ADG of bulls finished in a feedlot. The, difference in the value obtained to revenues total to carcass of $\$ 50.60$ between levels $0 \%$ and $30 \%$ of COS and $\$ 44.16$ to level $0 \%$ and $30 \%$ Of COS. It was found that bulls fed the $30 \%$ level with COS showed a variation of $75 \%$ more in revenue (R\$) $\mathrm{kg}^{-1}$ carcass compared to $0 \%$ level with COS, or a difference of $\$ 0.58 \mathrm{~kg}^{-1}$ of carcass between these levels, respectively, generating a difference of $\$ 5,623.80$ between amount of monthly net income for the $0 \%$ level of COS (\$941.37) and for the 30\% level COS (6,565.17). The ration with $30 \%$ of COS showed a cost of R $\$ 0.08$ lower than the diet with $0 \%$ of COS. Therefore the use of up to $30 \%$ of COS in the feeding of bulls keeps ADG and can generate a net revenue month ${ }^{-1}$ greater than $85 \%$ compared to diets without cottonseed.

Key words: Operating cost, average daily gain, net revenue

\section{Introdução}

No Brasil, mediante as pesquisas realizadas pelo Instituto Brasileiro de Geografia e Estatística- IBGE (BRASIL, 2012), o rebanho de bovino apresenta 212,8 milhões de cabeças. O Centro Oeste brasileiro detêm um terço do rebanho nacional de bovinos (72,7 milhões de cabeça) e o Mato Grosso contribui com 29,3 milhões de cabeças.

As atividades agro-econômicas desenvolvidas no estado de Mato Grosso utilizam apenas 30\% do seu território. Mesmo com uma utilização restrita, o Mato Grosso é o maior produtor nacional de algodão e soja, além de ser grande produtor de milho, álcool e açúcar (FRANCISCO, 2006). Sendo assim, a produção de co-produtos agroindustriais torna-se inevitável.

Com a diminuição das áreas de pastagem para o plantio de cana-de-açúcar e soja, e a sua estacionalidade de produção, tornam escassos alguns recursos alimentares, refletindo em elevação do custo de produção. A grande necessidade de produção de alimentos para ruminantes desafia os pesquisadores e técnicos a buscar novas alternativas de recursos alimentares, com objetivo de reduzir custos, facilitar o gerenciamento e aumentar a produtividade dos rebanhos (GERON et al., 2010).

A utilização de técnicas modernas e novas tecnologias geradas na nutrição animal normalmente propiciam um custo adicional na produção animal.
Porém, a implantação e o uso de técnicas adequadas ao sistema de produção podem proporcionar resultados positivos e reduzir os custos fixos, consequentemente, aumentar a lucratividade (PILAU; ROCHA; SANTOS, 2003).

A utilização de co-produtos agroindustriais na dieta de bovinos de corte terminados em confinamento representa uma alternativa para reduzir os custos de produção, principalmente o da alimentação e aumentar a produtividade do rebanho, além de proporcionar alto valor nutricional (GERON, 2007; GERON et al., 2012a). Entre estes co-produtos, destacam-se o caroço de algodão, a casca do grão da soja e o bagaço da cana-de-açúcar hidrolisado.

Alimentos alternativos (resíduos da agroindústria) como o caroço de algodão (CRA) tem-se mostrado uma excelente opção para uso em confinamentos (CRANSTON et al., 2006; GERON et al., 2010). Visto que a associação do alto teor de proteína com elevado conteúdo de energia faz com que ele facilite a formulação de dietas de custo mínimo.

OCRAé um co-produto da indústria têx til oriundo do beneficiamento e/ou descaroçamento visando á separação da fibra, sendo composto por línter, casca e amêndoa. A cada $10 \mathrm{~kg}$ de fibra de algodão produzida a campo resulta aproximadamente em $165 \mathrm{~kg}$ de caroço. Uma tonelada do mesmo produz 
cerca de $200 \mathrm{~kg}$ de óleo, $500 \mathrm{~kg}$ de farelo de algodão e $300 \mathrm{~kg}$ de casca (PESCE, 2008; ZEOULA, 2002).

Segundo Savastano (2007), o CRA é considerado um alimento de boa aceitabilidade na nutrição de ruminantes, e "completo", porque reúne características de alimento volumoso $(>18 \%$ de FB na MS), de concentrado protéico ( $>20 \%$ de PB na $\mathrm{MS}$ ) e de concentrado energético (rico em energia, $>65 \%$ de nutrientes digestíveis totais - NDT). De acordo com Valadares Filho, Paulino e Magalhães (2006) o CRA apresenta a seguinte composição bromatológica $82,0 \%$ de nutrientes digestíveis totais (NDT), 23,0\% de proteína bruta (PB), 44,0\% de fibra em detergente neutro (FDN) e 19,0\% de extrato etéreo (EE).

Para que a produção bovina seja economicamente viável e competitiva é necessário, entre outros fatores, proporcionar ao animal condições de exteriorizar o máximo desempenho de suas potencialidades genéticas através do fornecimento de alimentação balanceada e de baixo custo visando alcançar as condições de peso para abate o mais precoce possível (BARROS et al., 2010; GARCIA, 2005; GERON et al., 2012b).

A utilização de rações balanceadas que atendam os níveis de exigência nutricional para maximizar a eficiência de produção animal pode proporcionar aumento no custo de produção, o que pode tornar a atividade menos rentável. Assim, Ferreira et al. (1998) relataram que o consumo, o ganho médio diário e o rendimento de carcaça, são importantes parâmetros na avaliação do desempenho animal e da viabilidade econômica na produção de animais ruminantes.

O Brasil detém o maior rebanho comercial de bovinos no mundo, assim torna-se importante o conhecimento da análise econômica desta atividade, uma vez que o produtor passa a conhecer os resultados financeiros obtidos da atividade, por meio deste processo. Mediante aos resultados econômicos obtidos os produtores podem tomar suas decisões e tornar o sistema de produção mais rentável (LOPES; CARVALHO, 2002).

Segundo Geron et al. (2012b) e Reis (1998) a definição para o custo de produção é a soma de todos os valores recursos (insumos) e operações (serviços) utilizados no processo produtivo de certa atividade. O estudo dos custos tem a finalidade de se verificar como os recursos empregados em um processo de produção estão sendo remunerados, possibilitando também, verificar como está a rentabilidade da atividade, comparada a alternativas de emprego de tempo e capital (LOPES; CARVALHO, 2002).

Portanto objetivou-se avaliar neste estudo a viabilidade econômica e o custo das rações fornecidas a tourinhos terminados em confinamento alimentados com diferentes teores de inclusão de caroço de algodão - CRA $(0 \% ; 10 \% ; 20 \%$ e $30 \%)$, em rações contendo $85 \%$ de concentrado (casca do grão de soja - CGS e farelo de soja - FSA) e 15\% de volumoso (bagaço de cana-de-açúcar hidrolisado com cal - BIH).

\section{Material e Métodos}

Os dados de custo de produção analisados foram provenientes do confinamento de tourinhos da raça Nelore realizado durante os meses de julho a outubro (período de seca) no ano 2009 na região Sudoeste de Mato Grosso. O confinamento localizou-se na fazenda Lagoa do Guaporé no Município de Pontes e Lacerda - MT, situada a $15^{\circ} 19^{\prime} 05^{\prime \prime}$ de latitude Sul e $59^{\circ} 13$ ' $26^{\prime \prime}$ de longitude Oeste e a uma altitude de 295 metros.

As análises bromatológicas dos alimentos foram conduzidas no Laboratório de Análise de Alimentos e Nutrição Animal (LAANA) pertencente ao Departamento de Zootecnia da Universidade do Estado de Mato Grosso (UNEMAT) Campus Universitário de Pontes e Lacerda.

A instalação utilizada no confinamento dos tourinhos foi composta por quatro baias coletivas, cada baia possuía $140 \mathrm{~m}^{2}$ de área total, 8 metros linear de cocho e um bebedouro de concreto para 
cada duas baias. As medidas preventivas para controle das parasitoses e doenças foram feitas de acordo com as recomendações normais para esta atividade (vacinação e everminação), conforme Geron et al. (2010).

Foram utilizados 32 tourinhos (inteiros) da raça Nelore, com idade média de 36 meses e com peso corporal (PC) inicial médio de $424 \pm 25 \mathrm{~kg}$, em um sistema de confinamento para mensurar o consumo dos diferentes nutrientes presentes nas rações experimentais, ganho médio diário, custo da alimentação e viabilidade econômica da atividade. Os tourinhos foram identificados individualmente por brincos plásticos e alojados ao acaso em baias coletivas com capacidade para oito animais alimentados com rações contendo quatro teores $0 \%$; $10 \% ; 20 \%$ e $30 \%$ de caroço de algodão (CRA) por 90 dias.

Antes de entrar no período de adaptação, os animais foram pesados, e posteriormente, durante o período experimental foram efetuadas três pesagens, uma inicial e uma a cada 25 dias. Em todas as pesagens os animais foram submetidos a um jejum alimentar de 12 horas. Todas as pesagens foram realizadas por meio de balança eletrônica digital.

Após a distribuição dos tourinhos nos respectivos tratamentos foi realizado um teste de média para os valores do PC utilizando o programa Sistema de Análise Estatística e Genética - SAEG (UNIVERSIDADE FEDERALDE VIÇOSA, 1997), para a verificação se haveria diferença estatística para o PC dos diferentes grupos de animais. Desta maneira, buscou reduzir a variação da condição do escore corporal entre os diferentes tratamentos e homogeneizar as unidades experimentais (oito animais por tratamento) antes do inicio de avaliação experimental (GERON et al., 2010).

Os tourinhos passaram por um período de adaptação de 15 dias, visando à adaptação aos alimentos, às baias e ao próprio grupo. Neste período, a ração foi fornecida gradualmente até atingir a estabilidade do consumo de matéria seca (MS), com uma sobra de aproximadamente 10\% por dia, do total de MS fornecido em cada baia (tratamento).

Os alimentos concentrados utilizados na composição das rações experimentais foram o caroço de algodão (CRA), o farelo de soja (FSA), a casca do grão de soja (CGS) e como alimento volumoso foi utilizado o bagaço da cana-de-açúcar in natura hidrolisado com cal microprocessada (BIH).

O processamento de hidrólise do bagaço de cana-de-açúcar in natura foi realizado na Fazenda Lagoa do Guaporé - MT, onde foi adicionada a solução de cal micropocessada. Esta solução foi preparada antes do processo de hidrólise onde foi adicionado meio quilo de cal microprocessada para cada cinco litros de água distribuídos em cada cem quilos de bagaço de cana-de-açúcar in natura, segundo recomendação de Oliveira et al. (2007). A distribuição da solução de cal microprocessada foi realizada por meio de bomba manual de aspersão sobre uma camada de aproximadamente quinze centímetros de altura de bagaço de cana-de-açúcar in natura (BIN) previamente espalhada sobre um piso cimentado em um galpão coberto, sendo realizada posteriormente a homogeneização do BIN e em seguida providenciou o armazenado em um silo de superfície gerando o bagaço de cana-deaçúcar hidrolisado (BIH).

A composição bromatológica dos alimentos está demonstrada na (Tabela 1). As rações experimentais foram formuladas para apresentarem $15 \%$ de volumoso (BIH) e $85 \%$ de concentrado (CRA, FSAe CGS). As rações foram balanceadas para apresentar teores semelhantes de energia (66\% de NDT) e proteína bruta (12\%) segundo Valadares Filho, Paulino e Magalhães (2006), como demonstrado na Tabela 2. 
Tabela 1. Composição bromatológica dos alimentos experimentais.

\begin{tabular}{|c|c|c|c|c|c|c|c|c|c|}
\hline \multirow{2}{*}{ Alimentos } & \multirow{2}{*}{ MS (\%) } & \multicolumn{8}{|c|}{$\%$ na MS } \\
\hline & & $\mathrm{MO}$ & PB & $\mathrm{EE}$ & FDN & MM & $\mathrm{CHT}^{1}$ & $\mathrm{CNF}^{1}$ & $\mathrm{NDT}^{2}$ \\
\hline $\begin{array}{l}\text { Bagaço de cana-de-açúcar } \\
\text { hidrolisado (BIH) }\end{array}$ & 54,08 & 95,76 & 1,60 & 1,49 & 88,44 & 4,24 & 92,66 & 8,33 & 43,52 \\
\hline $\begin{array}{l}\text { Casca do grão de soja } \\
\text { (CGS) }\end{array}$ & 90,17 & 95,80 & 10.92 & 2,37 & 53,34 & 4,20 & 60,07 & 13,23 & 81,92 \\
\hline Caroço de algodão (CRA) & 90,28 & 96,20 & 19,11 & 17,02 & 69,24 & 3,80 & 82,52 & 6,48 & 68,77 \\
\hline Farelo de Soja (FSA) & 88,16 & 93,34 & 49,41 & 1,59 & 20,13 & 6,66 & 42,34 & 26,89 & 81,54 \\
\hline Calcário $^{2}$ & 99,27 & 0,46 & -- & -- & -- & 97,33 & -- & -- & -- \\
\hline Premix & 99,00 & 1,00 & -- & -- & -- & 99,00 & -- & -- & -- \\
\hline Sal branco ${ }^{2}$ & 99,07 & 10,71 & -- & -- & -- & 89,29 & -- & -- & -- \\
\hline
\end{tabular}

MS: matéria seca; MO: matéria orgânica; PB: proteína bruta; EE: extrato etéreo; FDN: fibra em detergente neutro; MM: matéria mineral; CHT: carboidratos totais ${ }^{1}$ (Snifeen et al., 1992), CNF: Carboidratos não estruturais e NDT: nutrientes digestíveis totais, ${ }^{2}$ (adaptado: VALADARES FILHO; PAULINO; MAGALHÃES, 2006).

Fonte: Elaboração dos autores.

Tabela 2. Composição percentual e bromatológica das rações experimentais.

\begin{tabular}{|c|c|c|c|c|c|}
\hline \multirow[t]{2}{*}{ Alimentos } & \multicolumn{4}{|c|}{$\begin{array}{c}\text { Teores de inclusão do caroço de algodão nas rações } \\
\text { experimentais }\end{array}$} & \multirow{2}{*}{$\begin{array}{l}\text { Custo R\$/ } \\
\mathrm{kg}\end{array}$} \\
\hline & $0 \%$ & $10 \%$ & $20 \%$ & $30 \%$ & \\
\hline \multicolumn{6}{|c|}{ Composição percentual das rações experimentais } \\
\hline Bagaço de cana-de-açúcar hidrolisado (BIH) & 15,0 & 15,0 & 15,0 & 15,0 & 0,19 \\
\hline Casca do grão de soja (CGS) & 73,1 & 66,7 & 59,9 & 52,7 & 0,73 \\
\hline Caroço de algodão (CRA) & 0,0 & 10,2 & 20,4 & 30,6 & 0,38 \\
\hline Farelo de Soja (FSA) & 10,2 & 6,4 & 2,1 & 0,0 & 0,48 \\
\hline Calcário & 0,85 & 0,85 & 0,85 & 0,85 & 0,03 \\
\hline Premix & 0,425 & 0,425 & 0,425 & 0,425 & 0,75 \\
\hline Sal branco & 0,425 & 0,425 & 0,425 & 0,425 & 0,20 \\
\hline Total & 100,0 & 100,0 & 100,0 & 100,0 & - \\
\hline \multicolumn{6}{|c|}{ Composição bromatológica (\% na MS) das rações experimentais } \\
\hline \multicolumn{6}{|l|}{ Variáveis } \\
\hline Matéria seca (MS) & 84,72 & 84,81 & 84,88 & 84,96 & - \\
\hline Materia orgânica (MO) & 93,97 & 94,11 & 94,23 & 94,35 & - \\
\hline Proteína bruta (PB) & 13,26 & 12,62 & 12,15 & 11,84 & - \\
\hline Extrato etéreo (EE) & 2,12 & 3,64 & 5,16 & 6,68 & - \\
\hline Fibra em detergente neutro (FDN) & 65,93 & 66,19 & 66,24 & 66,08 & - \\
\hline Fibra em detergente neutro (FDA) & 50,78 & 50,65 & 50,31 & 49,78 & - \\
\hline Matéria mineral (MM) & 6,01 & 5,87 & 5,75 & 5,63 & - \\
\hline Carboidratos totais (CHT) & 78,61 & 77,86 & 76,93 & 75,84 & - \\
\hline Carboidratos não fibrosos (CNF) & 13,66 & 12,45 & 11,30 & 10,20 & - \\
\hline Nutriente digestíveis totais (NDT) ${ }^{1}$ & 65,12 & 65,97 & 66,88 & 67,84 & - \\
\hline Custo $\mathrm{R} \$ / 100 \mathrm{~kg}$ de MS da ração & 61,11 & 58,49 & 55,34 & 52,95 & - \\
\hline
\end{tabular}

${ }^{1}$ Valores estimados segundo recomendação de Valadares Filho; Paulino e Magalhães (2006).

Fonte: Elaboração dos autores. 
Os animais receberam o volumoso $(\mathrm{BIH})$ e o concentrado três vezes ao dia, às sete da manhã (07h), doze (12h) e dezessete horas (17h). Os alimentos foram pesados em balança digital com capacidade de $500 \mathrm{~kg}$. Durante a condução do período de avaliação experimental foram realizadas amostragens dos alimentos para posterior análise química e bromatológica dos nutrientes, para determinar o consumo dos nutrientes.

Foram realizadas pesagens de sobras das diferentes rações experimentais diariamente, antes da primeira alimentação da manhã, durante o período de avaliação experimental. A cada três dias foram coletadas aproximadamente $10 \%$ do total das sobras para os diferentes teores de inclusão do CRA, os quais foram acondicionadas e congeladas (freezer) para posterior análise química e bromatológica.

As amostras do BIH e das sobras passaram primeiramente pelo processo de pré-secagem em estufa de ventilação forçada a $60{ }^{\circ} \mathrm{C}$ por 72 horas até obtenção do peso constante. Após a pré-secagem do $\mathrm{BIH}$, todos os alimentos experimentais passaram por processo de moagem em moinho willer com peneira de um milímetro.

A determinação do teor de MS dos alimentos e das sobras estudadas foi realizada em estufa a $105^{\circ} \mathrm{C}$ por aproximadamente 12 horas. $\mathrm{O}$ teor de nitrogênio dos alimentos estudados e das sobras foi obtido pelo método semi-micro-Kjeldahl, usando 6,25 como fator de conversão para $\mathrm{PB}$, a matéria mineral $(\mathrm{MM})$ e a matéria orgânica (MO) foi realizada pelo método por incineração em forno mufla a $600{ }^{\circ} \mathrm{C}$ e o teor de extrato etéreo (EE) foi determinado pela extração por lavagem com éter de petróleo, segundo citações de Silva e Queiroz (2002).

A determinação da fibra em detergente neutro (FDN) e fibra em detergente ácido (FDA) dos alimentos e das sobras foram realizadas de acordo com as metodologias descritas por Van Soest, Robertson e Lewis (1991).

A partir dos resultados das análises de proteína $(\mathrm{PB})$, extrato etéreo (EE) e matéria mineral (MM) foi realizado o cálculo dos carboidratos totais (CHT), de acordo com a equação de Sniffen et al. (1992): $\mathrm{CHT}=100-(\% \mathrm{~PB}+\% \mathrm{EE}+\% \mathrm{MM})$ e para os carboidratos não fibrosos $(\mathrm{CNF})$ onde: $\mathrm{CNF}=$ $\%$ CHT - \%FDN. O valor de NDT dos alimentos foi obtido segundo citações de Valadares Filho, Paulino e Magalhães (2006).

Foi considerado o abate realizado em frigorífico comercial para avaliação do peso de carcaça quente e do rendimento de carcaça por meio da pesagem das carcaças ao final da linha de abate (EZEQUIEL et al., 2006; BARROS et al., 2009).

Para efetuar a análise do custo operacional por carcaça e por quilograma de carcaça dos animais experimentais, foram considerados o preço de mercado dos alimentos (CRA, FSA, CGS e BIH) e o valor pago na região pela carcaça de bovinos para o ano base de 2012, de acordo com as recomendações de Geron et al. (2012b) e Santello et al. (2006).

O custo dos alimentos concentrados foi calculado com dados de insumos e frete utilizados para a sua aquisição. Ressalta-se que para todos os valores foi utilizado o ano base de 2012 e no local em que se conduziu este estudo, município de Pontes e Lacerda - MT. O custo da tonelada dos diferentes alimentos utilizados no confinamento foi de R \$400,00 (CRA), de $\mathrm{R} \$ 730,00$ (CGS), de R \$1.030,00 (FSA) e de R\$ 190,00 (BIH). O custo da ração expressa para 100 $\mathrm{kg}$ de matéria seca foi de $\mathrm{R} \$ 67,15 ; \mathrm{R} \$ 62,64 ; \mathrm{R} \$$ 57,33 e R\$ 53,99; respectivamente, para os níveis de $0 \% ; 10 \%, 20 \%$ e $30 \%$ de inclusão de CRA.

A planilha de cálculo do custo de produção foi montada com dados coletados no experimento, referentes a 32 tourinhos terminados em confinamento recebendo diferentes níveis de inclusão de CRA. Entretanto, para que os resultados pudessem ser comparados, considerou-se módulo de 100 animais tratamento ${ }^{-1}$ para realização dos cálculos de viabilidade econômica segundo Santello et al. (2006).

O consumo de sal mineral médio para cada animal foi de $70 \mathrm{~g} \mathrm{dia}^{-1}$, disponibilizado em cocho 
específico dentro do confinamento, este valor foi multiplicado pelo período de suplementação dos bovinos em confinamento para o modulo de 100 animais e o custo do sal mineral foi de $\mathrm{R} \$ 1,50 \mathrm{~kg}^{-1}$.

O custo com a everminação foi calculado baseado no custo do princípio ativo (ivermectina ${ }^{\circledR}$ ), o qual foi ministrado na dose de $1,0 \mathrm{~mL}$ para cada $50 \mathrm{~kg}$ de $\mathrm{PC}$, no valor de $\mathrm{R} \$ 0,15$ para cada $1,0 \mathrm{~mL}$ animal $^{-1}$.

O custo com mão-de-obra foi baseado no valor da diária vigente no ano base de 2012, na região de Pontes e Lacerda - MT de R\$20,73 para o desenvolvimento da atividade com 100 animais, ou seja, foi utilizado um valor de R\$ 622,00 mês 1100 animais $^{-1}$. Foi considerado para o cálculo de custo total de mão-de-obra a multiplicação do custo da diária pelo tempo médio que os animais permaneceram no confinamento (90 dias).

Foi calculado o custo da aquisição dos animais considerando o PC inicial. O custo da compra dos animais foi de $\mathrm{R} \$ 65,00 @^{-1}$, este valor estava vigente no ano base de 2012.

A determinação do valor de despesa total para os diferentes níveis de inclusão de CRA foi obtida pela soma de custo da compra de animais, suplementação concentrada, everminação, mineralização e mãode-obra segundo Geron et al. (2012b) e Santello et al. (2006).

Os tourinhos foram comercializados na região de Pontes e Lacerda - MT no valor de R\$ 92,00 @-1 da carcaça no ano base de 2012.

Foi utilizado um delineamento experimental inteiramente casualizado com quatro tratamentos e oito repetições por tratamento. Os dados de ganho médio diário (GMD) dos diferentes níveis de inclusão do CRA foram submetidos à análise de variância por meio do programa Sistema de Análise Estatística e Genética - SAEG (UNIVERSIDADE FEDERAL DE VIÇOSA, 1997) e as diferenças obtidas foram testadas por meio de análise de regressão considerando $5 \%$ de significância. Os dados de custo de produção de tourinhos, não passaram por análise estatística, uma vez que a diferenças econômica encontradas basearam-se na maior lucratividade.

\section{Resultados e Discussão}

O valor de consumo de matéria seca (MS), ganho médio diário expresso em $\mathrm{kg} \mathrm{dia}^{-1}$, bem como o valor do peso corporal (PC) inicial e final expressos em $\mathrm{kg}$ animal ${ }^{-1}$ de tourinhos terminados em confinamento não apresentaram diferença $(p>0,05)$ com a inclusão dos diferentes teores de CRA nas rações experimentais contendo coprodutos agroindustriais, com valor médio de 12,10 $\mathrm{kg} \mathrm{dia}^{-1} ; 1,41 \mathrm{~kg} \mathrm{dia}^{-1} ; 425,9 \mathrm{~kg}$ animal $^{-1}$ e $552,65 \mathrm{~kg}$ animal $^{-1}$, respectivamente (Tabela 3 ).

A análise da viabilidade econômica da produção de tourinhos Nelores terminados em confinamento alimentados com diferentes teores de CRA pode ser observada na Tabela 3. Foi observada uma diferença no valor da receita total por carcaça de R\$ 50,60 entre os teores de $0 \%$ e $10 \%$ de CRA e de $\mathrm{R} \$ 44,16$ para os teores $0 \%$ e $30 \%$ de CRA, provavelmente esta diferença de $\mathrm{R} \$ 6,44$ na receita total por carcaça entre a comparação dos teores de $0 \%$ a $10 \%$ e de $0 \%$ a $30 \%$ de CRA, pode ter sido influenciado pelo peso corporal final dos animais alimentados com $10 \%$ e $30 \%$ de CRA, o qual apresentou uma diferença de $2,00 \mathrm{~kg}$ entre esses teores de inclusão do CRA. 
Tabela 3. Valor de consumo de matéria seca (CMS) $\mathrm{kg}_{\text {animal }}{ }^{-1} \mathrm{dia}^{-1}$, ganho médio diário $\left(\mathrm{kg}_{\text {animal }}{ }^{-1}\right.$ dia $\left.^{-1}\right)$ custo das rações experimentais $(\mathrm{R} \$)$ e análise da viabilidade econômica da produção de tourinhos terminados em confinamento com diferentes teores de caroço de algodão (CRA).

\begin{tabular}{|c|c|c|c|c|c|}
\hline \multirow[t]{2}{*}{ Variáveis } & \multicolumn{4}{|c|}{$\begin{array}{l}\text { Teores de inclusão de caroço de algodão nas rações } \\
\text { experimentais }\end{array}$} & \multirow[t]{2}{*}{$\% \mathrm{CV}^{* 2}$} \\
\hline & $0 \%$ & $10 \%$ & $20 \%$ & $30 \%$ & \\
\hline Consumo de MS kg dia ${ }^{-1}$ & 11,91 & 12,27 & 12,10 & 12,11 & - \\
\hline Peso corporal inicial $(\mathrm{kg})^{\mathrm{NS}}$ & 423,90 & 429,80 & 423,90 & 426,00 & 3,67 \\
\hline Peso corporal final $(\mathrm{kg})^{\mathrm{NS}}$ & 543,10 & 559,00 & 550,50 & 557,00 & 4,47 \\
\hline Ganho médio diário $\left(\mathrm{kg} \mathrm{dia}^{-1}\right)^{\mathrm{NS}}$ & 1,33 & 1,44 & 1,41 & 1,46 & 13,53 \\
\hline Rendimento de carcaça $(\%)^{* 1}$ & 52,00 & 52,00 & 52,00 & 52,00 & - \\
\hline Peso da carcaça quente $(\mathrm{kg})$ & 282,41 & 290,68 & 286,26 & 289,64 & - \\
\hline Peso da carcaça quente @ & 18,83 & 19,38 & 19,08 & 19,31 & - \\
\hline Número de animais (modulo de 100) & 100,00 & 100,00 & 100,00 & 100,00 & - \\
\hline Total de carcaça quente kg & $28.241,0$ & $29.068,0$ & $28.626,0$ & $28.964,0$ & - \\
\hline Total de carcaça quente @ & $1.882,73$ & $1.937,87$ & $1.908,40$ & $1.930,93$ & - \\
\hline Valor $(\mathrm{R} \$)$ de comercialização da @ & 92,00 & 92,00 & 92,00 & 92,00 & - \\
\hline Receita total por carcaça $(\mathrm{R} \$)$ & $1.732,36$ & $1.782,96$ & $1.755,36$ & $1.776,52$ & - \\
\hline Receita por kg de carcaça ( $\mathrm{R} \$$ ) & 6,13 & 6,13 & 6,13 & 6,13 & \\
\hline Receita total $(\mathrm{R} \$)$ & $173.236,0$ & $178.296,0$ & $175.536,0$ & $177.652,0$ & - \\
\hline \multicolumn{6}{|l|}{ Despesas } \\
\hline A) Custo da compra dos animais ( $\mathrm{R} \$ 65,00 @$ ) & $95.550,0$ & $96.850,0$ & $95.550,0$ & $96.005,0$ & - \\
\hline Custo $(\mathrm{R} \$)$ das rações $\mathrm{kg}$ & 0,67 & 0,63 & 0,57 & 0,54 & - \\
\hline Custo (R\$) da ração animal dia ${ }^{-1}$ & 7,98 & 7,73 & 6,90 & 6,54 & - \\
\hline B) Custo $(\mathrm{R} \$)$ da ração 100 animais 90 dias $^{-1}$ & $71.820,0$ & $69.570,0$ & $62.100,0$ & $58.860,0$ & - \\
\hline Custo (R\$) do sal mineral kg & 1,50 & 1,50 & 1,50 & 1,50 & - \\
\hline Consumo de sal mineral animal ${ }^{-1} \mathrm{dia}^{-1}(\mathrm{~kg})$ & 0,070 & 0,070 & 0,070 & 0,070 & - \\
\hline Custo (R\$) do sal mineral animal ${ }^{-1}$ dia $^{-1}$ & 0,11 & 0,11 & 0,11 & 0,11 & - \\
\hline $\begin{array}{l}\text { C) Custo ( } \mathrm{R} \$ \text { ) do sal mineral } 100 \text { animais }^{-1} 90 \\
\text { dias }^{-1}\end{array}$ & 990,00 & 990,00 & 990,00 & 990,00 & - \\
\hline Custo (R\$) do vermífugo animal 90 dias $^{-1}$ & 1,27 & 1,27 & 1,27 & 1,27 & - \\
\hline $\begin{array}{l}\text { D) Custo (R\$) do vermífugo } 100 \text { animais } 90 \\
\text { dias }^{-1}\end{array}$ & 127,00 & 127,00 & 127,00 & 127,00 & \\
\hline Custo da mão-de-obra (diária) R\$ & 20,73 & 20,73 & 20,73 & 20,73 & - \\
\hline Total de dias dedicado a atividade & 90 & 90 & 90 & 90 & - \\
\hline E) custo total com mão-de-obra & $1.865,70$ & $1.865,70$ & $1.865,70$ & $1.865,70$ & - \\
\hline Despesa total $(\mathrm{R} \$)(A+B+C+D+E)$ & $170.352,70$ & $169.402,70$ & $160.632,70$ & $157.847,70$ & - \\
\hline Custo operacional por carcaça (R\$) & $1.703,53$ & $1.694,03$ & $1.606,33$ & $1.578,48$ & - \\
\hline Custo operacional $\mathrm{kg}^{-1}$ de carcaça $(\mathrm{R} \$$ ) & 6,03 & 5,83 & 5,61 & 5,45 & - \\
\hline Receita líquida $\mathrm{kg}^{-1}$ de carcaça $(\mathrm{R} \$)$ & 0,10 & 0,30 & 0,52 & 0,68 & - \\
\hline Receita líquida total (R\$) & $2.824,10$ & $8.720,40$ & $14.885,52$ & $19.695,52$ & - \\
\hline Receita líquida por mês $(\mathrm{R} \$)$ & 941,37 & $2.906,80$ & $4.961,84$ & $6.565,17$ & - \\
\hline
\end{tabular}

${ }^{{ }_{1}}$ Barros et al. (2009); ${ }^{*_{2}} \mathrm{CV}=$ Coeficiente de variação.

Fonte: Elaboração dos autores. 
Vale ressaltar que não houve diferença ( $>>0,05)$ para o GMD entre os diferentes teores de inclusão do CRA na dieta de tourinhos Nelores em confinamento. Entretanto, quando esses valores foram extrapolados para modulo de 100 animais tratamento $^{-1}$ gerou uma diferença monetária significativa em relação à receita total da atividade desenvolvida com valores de $\mathrm{R} \$ 5.060,00$ entre os teores de $0 \%$ e $10 \%$ de CRA e de R $\$ 4.416,00$ entre os teores $0 \%$ e $30 \%$ de CRA, respectivamente.

Cabe salientar que a receita total $(\mathrm{R} \$)$ por si só não é um bom parâmetro de avaliação da viabilidade econômica da atividade, uma vez que o produtor deverá considerar os valores de despesas referentes ao custo da alimentação, da compra dos animais, do sal mineral, vermífugo e de mão-de-obra utilizada para o desenvolvimento da atividade (COSTA et al., 2005; GERON et al., 2012b).

Observou-se que a maior amplitude no valor das despesas expressas em reais $(\mathrm{R} \$)$ foi em relação à alimentação animal, a qual apresentou uma diferença de $\mathrm{R} \$ 0,08 \mathrm{~kg}^{-1}$ de $\mathrm{MS}$, entre as rações com $0 \%$ e $30 \%$ de CRA. Esses valores corroboram com os relatos de Geron (2007) e Geron et al. (2010) que os co-produtos agroindustriais normalmente contribuem para a redução do custo da alimentação. Esse fato ficou mais evidenciado quando se utilizou o modulo de 100 animais tratamento ${ }^{-1}$, o qual gerou uma diferença de $\mathrm{R} \$ 12.960,00$ no custo da ração total entre os teores de $0 \%$ e 30\% de CRA, na dieta de tourinhos mantidos em confinamento por 90 dias (Tabela 3).

Os valores de despesa com sal mineral, everminação e mão-de-obra não apresentaram variação para os diferentes teores de inclusão do CRA, entretanto para a despesa com a compra dos animais foi observado uma variação máxima de R\$ $1.300,00$ entre os diferentes teores de inclusão do CRA. Indicando que a diferença observada para o valor de despesa total $(\mathrm{R} \$ 12.505,00)$ entre os teores $0 \%$ e 30\% de CRA, foi devido principalmente à redução no custo da alimentação proporcionado pela inclusão do CRA na dieta de tourinhos Nelores terminados em confinamento.

$\mathrm{O}$ custo operacional carcaça ${ }^{-1}$ e $\mathrm{o}$ custo operacional $\mathrm{kg}^{-1}$ de carcaça para o teor de inclusão de $30 \%$ de CRA foi 7,3\% e 9,6\% menor em relação ao teor de $0 \%$ de inclusão de CRA, para modulo de 100 animais tratamento ${ }^{-1}$. Essas variações percentuais diagnosticadas entre esses respectivos teores de inclusão de CRA (0\% e 30\%) representaram uma diferença financeiramente do custo operacional carcaça $^{-1}$ de $\mathrm{R} \$ 125,05$ e para o custo operacional $\mathrm{kg}^{-1}$ de carcaça de $\mathrm{R} \$ 0,58$ com variação de $\mathrm{R} \$ 6,03$ a $\mathrm{R} \$ 5,45$, respectivamente, para os referidos teores de inclusão de CRA (Tabela 3).

Segundo Costa, Ceretta e Gonçalves (2006), a viabilidade econômica da produção de bovinos em sistema tradicional e intensivo apresentaram valores de custo de produção (custo operacional arroba $^{-1}$ ) de $\mathrm{R} \$ 53,25$ e R\$111,96, respectivamente. No presente estudo o custo operacional por arroba variou de $\mathrm{R} \$$ 113,52 a $\mathrm{R} \$ 105,23$ para os teores de $0 \%$ e $30 \%$ de inclusão de CRA, respectivamente.

Foi verificado que o teor com $30 \%$ de CRA apresentou uma variação de 75,3\% maior na receita (R\$) $\mathrm{kg}^{-1}$ de carcaça de tourinhos em relação ao teor com $0 \%$ de CRA, ou seja, uma diferença de $\mathrm{R} \$ 0,58$ entre esses tratamentos com uma amplitude de variação de $\mathrm{R} \$ 0,68$ a $\mathrm{R} \$ 0,10$, respectivamente. Este fato indica que a utilização de até $30 \%$ de CRA na alimentação de tourinhos confinado mantém o GMD e pode gerar uma receita líquida mês ${ }^{-1} 85 \%$ maior em relação aos animais alimentados com o farelo de soja sendo a principal fonte de proteína (ração com $0 \%$ de inclusão de CRA).

O lucro e o sucesso de um confinamento dependem de diversos fatores que iniciam com a escolha do peso inicial e do preço pago pelo boi magro. O planejamento estratégico do confinamento, considerando a melhor época de aquisição dos insumos e o período de compra dos animais. Segundo Ezequiel et al. (2006), recomenda-se que todos os fatores ligados ao custo de produção de bovinos em 
confinamento sejam equacionados e controlados periodicamente para que o resultado final seja satisfatório, de modo que o lucro proporcionado pelo ganho de peso seja maximizado por meio do aumento na eficiência de utilização dos alimentos ou pelo menor preço de aquisição.

Estudo realizado por Sampaio et al. (1998), para avaliar o efeito da suplementação protéica sobre o crescimento e a viabilidade econômica de bezerros mestiços Chanchim confinados pós-desmama, demonstrou que a receita líquida média gerada por arroba de carcaça foi R \$ 15,52 para a utilização do farelo de algodão e soja além da utilização da soja integral. No presente estudo obteve-se uma receita líquida média por arroba de $\mathrm{R} \$ 6,00$; entretanto observou uma amplitude de variação de $\mathrm{R} \$ 1,50$ a R $\$ 10,20$ entre o teor com $0 \%$ e $30 \%$ de CRA, respectivamente.

\section{Conclusões}

Conclui-se que o teor de $30 \%$ de caroço de algodão em rações constituída por co-produtos agroindustriais fornecida á tourinhos terminados em confinamento apresenta menor custo e melhor viabilidade econômica sem influenciar no ganho médio diário e o consumo de matéria seca e propicia uma receita liquida mensal $85 \%$ maior em relação a tourinhos terminados em confinamento sem caroço de algodão.

\section{Agradecimentos}

Ao Conselho Nacional de Desenvolvimento Cientifico e Tecnológico (CNPq) por ter financiado a execução do presente estudo. A Fundação de Amparo à Pesquisa do Estado de Mato Grosso (FAPEMAT) por ter concedido bolsas de iniciação cientifica aos acadêmicos do Curso de Zootecnia para auxiliarem o desenvolvimento do estudo. Ao senhor Paulo Cárdia proprietário da fazenda Lagoa do Guaporé por ter apoiado e auxiliado no desenvolvimento da pesquisa cedendo as instalações e mão-de-obra da fazenda. A empresa Suprema Nutrição Animal, por ter confeccionado os concentrados utilizados no estudo.

\section{Referências}

BARROS, R. C.; ROCHA JÚNIOR, V. R.; SILVA, F. V.; ALVES, D. D.; SALES, E. C. J.; FRANCO, M. O.; REIS, S. T.; SOUZA, A. S. Cana-de-açúcar ou bagaço de cana amonizado com uréia em substituição à silagem de sorgo para bovinos de corte confinados. Revista Brasileira de Saúde e Produção Animal, Salvador, v. 10, n. 2, p. 278292, 2009.

BARROS, R. C.; ROCHA JUNIOR, V. R.; SOUZA, A. S.; FRANCO, M. O.; OLIVEIRA, T. S.; MENDES, G. A.; PIRES, D. A. A.; SALES, E. C. J.; CALDEIRA, L. A. Viabilidade econômica da substituição da silagem de sorgo por cana-de-açúcar ou bagaço de cana amonizado com ureia no confinamento de bovinos. Revista Brasileira de Saúde e Produção Animal, Salvador, v. 11, n. 3, p. 555-569, 2010.

BRASIL. Instituto Brasileiro de Geografia e Estatística - IBGE. Banco de dados Agregados - SIDRA. Rio de Janeiro, 2012. Disponível em: <http://www.sidra.ibge. gov.br/>. Acesso em: 15 jun. 2013.

COSTA, L. B.; CERETTA, P. S.; GONÇALVES; M. B. F.; SONAGLIO, C. M.; ZAMBERLAN, C. O. Viabilidade econômica da atividade pecuária em propriedade de ciclo completo: uma simulação. In: CONGRESSO INTERNACIONAL DE CUSTOS, 9., 2005, Florianópolis. Anais... Florianópolis: UCLA, 2005. p. 45-46.

COSTA, L. B.; CERETTA, P. S.; GONÇALVES; M. B. Viabilidade econômica: análise da bovinocultura de corte. Informações Econômicas, São Paulo, v. 36, n. 8, p. 123-129, 2006.

CRANSTON, J. J.; RIVERA, J. D.; GALYEAN, M. L.; BRASHEARS, M. M.; BROOKS, J. C.; MARKHAM, C. E.; MCBETH, L. J.; KREHBIEL, C. R. Effects of feeding whole cottonseed and cottonseed products on performance and carcass characteristics of finishing beef cattle. Journal of Animal Science, Champaign, v. 84, n. 8 , p. 2186-2199, 2006.

EZEQUIEL, J. M. B.; GALATI, R. L.; MENDES, A. R.; FATURI, C. Desempenho e características de carcaça de bovinos Nelore em confinamento alimentados com bagaço de cana-de-açúcar e diferentes fontes energéticas. Revista Brasileira de Zootecnia, Viçosa, MG, v. 35, n. 5, p. 2050-2057, 2006. 
FERREIRA, M. A.; VALADARES FILHO, S. C.; COELHO DA SILVA, J. F.; PAULINO, M. F.; VALADARES, R. F. D.; CECON, P. R.; MUNIZ, E. B. Consumo, conversão alimentar, ganho de peso e características de carcaça de bovinos F1 Simental e Nelore. Revista Brasileira de Zootecnia, Viçosa, MG, v. 28, n. 2, p. 343-351, 1998.

FRANCISCO, N. Fórum de meio ambiente: Vettorato propõe incentivo para produtores rurais. Cuiabá: SEDUC, 2006. Disponível em: <www.seduc.mt.gov.br/conteudo. php?sid $>$. Acesso em: 31 mar. 2010.

GARCIA, J. Suplementação para novilhos em pastagens de Braquiária nos períodos da seca e de transição secaágua. 2005. Tese (Doutorado em Zootecnia) - Curso de Pós-graduação em Zootecnia. Universidade Estadual de Maringá, Maringá.

GERON, L. J. V. Utilização de resíduos agroindustriais na alimentação de animais de produção. Publicações em Medicina Veterinária e Zootecnia - Pubvet, Londrina, v. 1, n. 9, p. 110-125, 2007.

GERON, L. J. V.; MEXIA, A. A.; GARCIA, J.; SILVA, M. M.; ZEOULA, L. M. Suplementação concentrada para cordeiros terminados a pasto sobre custo de produção no período da seca. Semina: Ciências Agrárias, Londrina, v. 33, n. 2, p. 797-808, 2012 b.

GERON, L. J. V.; MEXIA, A. A.; GARCIA, J.; ZEOULA, L. M.; GARCIA, R. R. F.; MOURA, D. C. Desempenho de cordeiros em terminação suplementados com caroço de algodão (Gossypium hirsutum L.) e grão de milho moído (Zea mays L.). Archives of Veterinary Science, Curitiba, v. 17, n. 4, p. 34-42, $2012 \mathrm{a}$.

GERON, L. J. V.; PAULA, E. J. H.; RODRIGUES, D. N.; MOURA, D. C.; ALVES JÚNIOR, R. T.; RUPPIN, R. F. Consumo de nutrientes de tourinhos confinados alimentados com rações de alto concentrado contendo co-produtos agroindustriais. Revista de Ciências AgroAmbientais, Alta Floresta, v. 8, n. 1, p. 31-44, 2010.

LOPES, M. A.; CARVALHO, F. M. Custo de produção do gado de corte. Lavras: UFLA, 2002. 47 p. (Boletim Agropecuário, 47).

OLIVEIRA, M. D. S.; ANDRADE, A. T.; BARBOSA, J. C.; SILVA, T. M.; FERNANDES, A. R. M.; CALDEIRÃO, E.; CARABOLANTE, A. Digestibilidade da cana-de-acúcar hidrolisada, in natura e ensilada para bovinos. Ciência Animal Brasileira, Goiânia, v. 8, n. 1, p. 41-40, 2007.

PESCE, D. M. C. Efeito da dieta contendo caroço de algodão no desempenho, características quantitativas da carcaça e qualitativas da carne de novilhos Nelore confinados. 2008. Tese (Doutorado em Zootecnia) -
Faculdade de Zootecnia e Engenharia de Alimentos. Universidade de São Paulo, Pirassununga.

PILAU, A.; ROCHA, M. G.; SANTOS, D. T. Análise econômica de sistemas de produção para recria de bezerras de corte. Revista Brasileira de Zootecnia, Viçosa, MG, v. 32, n. 4, p. 966-976, 2003.

REIS, A. J. Economia aplicada à administração. Lavras: UFLA, 1998. 126 p. (Apostila).

SAMPAIO, A. A. M.; BRITO, R. M.; VIEIRA, P. F.; TOSI, H. Efeito da suplementação protéica sobre crescimento, terminação e viabilidade econômica de bezerros mestiços Canchim confinados pós desmame. Revista Brasileira de Zootecnia, Viçosa, v. 27, n. 4, p. 823-831, 1998.

SANTELlO, G. A.; MACEDO, F. A. F.; MEXIA, A. A.; SAKAGUTI, E. S.; DIAS, F. J.; PEREIRA, M. F. Característica de carcaça e análise do custo de sistemas de produção de cordeiros $1 / 2$ Dorset Santa Inês. Revista Brasileira de Zootecnia, Viçosa, MG, v. 35, n. 4, p. $1852-$ 1859, 2006.

SAVASTANO, S. Caroço de algodão na alimentação bovina. São Paulo: Cati, 2007. Disponível em: <http:// www.cati.sp.gov.br/Cati/_tecnologias/bovinocultura/ caroco_algodao.php>. Acesso em: 30 mar. 2012.

SILVA, D. J.; QUEIROZ, A. C. Análise de alimentos: métodos químicos e biológicos. 2. ed. Viçosa, MG: UFV, 2002. 178 p.

SNIFFEN, C. J.; O'CONNOR, J. D.; VAN SOEST, P. J.; FOX, D. G.; RUSSELL, J. B. A net carbohydrate and protein system for evaluating cattle diets: II. Carbohydrate and protein availability. Journal of Animal Science, Champaign, v. 70, n. 10, p. 3562-3577, 1992.

UNIVERSIDADE FEDERAL DE VIÇOSA - UFV. Sistema de análises estatísticas e genéticas - SAEG. Viçosa: UFV, 1997. 150 p. (Manual do usuário).

VALADARES FILHO, S. C.; PAULINO, P. V. R.; MAGALHÃES, K. A. Exigências nutricionais de zebuínos e tabelas de composição de alimentos BR-corte. Viçosa: UFV, DZO, 2006. 142 p.

VAN SOEST, P. J.; ROBERTSON, J. B.; LEWIS, B. A. Methods for dietary fiber neutral detergent fiber, and nostarch polysaccharides in relation to animal nutrition. Journal of Dairy Science, Champaign, v. 74, n. 12, p. 3583-3597, 1991.

ZEOULA, L. M. Alimentos usados na alimentação animal. In: CURSO DE ATUALIZAÇÃO POR TUTORIA À DISTÂNCIA - ATUALIZAÇÃO DA PRODUÇÃO DE BOVINOS DE CORTE, 1., 2002, Maringá. Anais... Maringá: FADEC, 2002. CD-ROM. 
